\title{
THE SEASONAL PREVALENCE OF PNEUMONIC FEVER.a
}

\section{By John William Moore, B.A., M.D., Univ, Dubl., F.R.C.P.I.}

Is April, 1875, Dr. T. W. Grimshaw, now Registrar-General for Ireland, and I, read before the Medical Society of the King and Queen's College of Physicians a paper on what we ventured to call "Pythogenic Pneumonia." This paper, which was published in the number of the Dublin Journal of Medical Science for May, $1875, \mathrm{~b}$ was based upon observations of pneumonia in Steevens' and Cork-street Hospitals, Dublin, during the summer of 1874 , when an epidemic of the disease prevailed in the Irish capital ; as well as upon an analysis of the statistics of death from bronchitis and pneumonia registered in Dublin during nine years ending with 1873. In the same communication, the meteorological and epidemic conditions of 1874 were discussed, and our researches seemed to warrant us in drawing the following conclusions :-

1. That the bibliography of pneumonia indicates the existence of a form of the disease which arises under miasmatic influences, and is contagious.

2. That this view is supported by the relation which exists between this form of pneumonia and certain zymotic affections-notably, enteric fever and cholera-and by the resemblance between it and epizoôtic pleuro-pneumonia.

3. That its ætiology justifies us in regarding the disease as a zymotic affection and in naming it "pythogenic pneumonia."

4. That pythogenic pneumonia presents peculiar clinical features which enable us to distinguish it from ordinary pneumonia.

5. That much of the pneumonia which prevailed in Dublin during 1874 was of this pythogenic character.

6. That whereas ordinary pneumonia is specially prevalent during a continuance of cold, dry weather, with high winds and extreme variations in temperature, pythogenic pneumonia reaches its maximum during tolerably warm weather, accompanied with a dry air, deficient rainfall, hot sun and rapid evaporation.

The years which have elapsed since the publication of this paper on "Pythogenic Pneumonia" have been fruitful in the literature of the subject to an unprecedented degree. Among the many monographs on pneumonia which have of late appeared, perhaps the most valuable are that by Dr. August Hirsch, Professor of Medicine in the University of Berlin,

\footnotetext{
a Reprinted, by permission, from the Transactions of the Ninth Session of the International Medical Congress. Volume V., page 45. Washington, D.C., U.S.A. 1887.

Vol. LIX., No. 41. Third Series, page 399.
} 
on the Geographical and Historical Pathology of the Disease, and that by the late Dr. C. Friedländer, of Berlin, on the "Micrococci of Pneumonia."

Hirsch, after pointing out that pneumonia, even in its narrowest acceptation of fibrinous or so-called croupous pneumonia, is an anatomical term that includes several inflammatory processes differing from one another in their ætiology, goes on to observe that the prevalence of the malady depends very decidedly upon certain influences of season and weather. He gives an elaborate table of percentages of pneumonic prevalence in the several months at a large number of places in Europe and America. According to this table, the largest number of cases falls in the months from February to May; the smallest number in the period from July to September. Taking the average for all the places mentioned in the table, it appears that 34.7 per centum of the patients were attacked in spring (March to May, inclusive); 29.0 in winter (December to February); 18.3 in autumn (September to November); and 18.0 in summer (June to August). The combined percentage for winter and spring is 63.7 ; that for summer and autumn is $36 \cdot 3$. If the number of cases in summer be taken as 1 , then autumn has 1.02 , winter $1 \cdot 6$ and spring 1.9 . Nearly all the recorded epidemics of pneumonia have occurred in winter and spring. From the foregoing considerations, Hirsch confidently concludes that the origin of the malady is dependent on weather influences proper to winter and spring, and more particularly on sudden changes of temperature and considerable fluetuations in the proportion of moisture in the air. He holds that any exceptionally large number of cases of "inflammation of the lungs" at the other seasons, more especially in summer, has coincided with the prevalence of the same meteorological conditions phenomenally at that season.

"But that conclusion," he goes on to say, "is still further borne out by the fact that in those northern regions (Rassia, Sweden, Denmark, Germany, England, North of France, and Northern States of the American Union) where the most sudden and severe changes of temperature fall in spring, the largest number of cases is met with in spring, also; while in the warmer and sub-tropical countries (Italy, islands of the Mediterranean, Spain and Portugal, Greece, Algiers, Sonthern States of the Union, Chili and Peru), which are subject to those meteorological influences, for the most part, in winter, it is winter that represents the proper season of pneumonia. And that applies not merely to sporadic cases, but, in part, at least, to epidemic outbreaks of the malady as well. One other fact deserves to be noticed bere, namely, that those traets of country, especially

a "Handbook of Geographical and Historical Pathology." Vol. III. Translated from the Second German Edition, by Cbarles Creighton, M.D. London : The New Sydenham Society. 1886.

b Fortachritte der Medicin. Band 1, Heft 22, Nov. 82, 1888. Translated for the New Sydenham Society. By Edgar Thurston. 1886. 
in the tropics, which are highly favoured in their climate or in the steadiness of the temperature from day to day (Egypt, many parts of India, including Bengal and the plain of Burmah, California, etc.), are subject to pneumonia to a comparatively slight extent."

In the paper on "Pythogenic Pneumonia," by Dr. Grimshaw and myself, will be found a Table, compiled from the returns of the Registrar-General for Ireland, which shows the number of deaths from bronchitis and pneumonia registered in the Dublin Registration District in each quarter of the nine years, 1865-1873, inclusive. According to that Table, of every 100 deaths from bronchitis, 44 on the average occurred in the first quarter of the year, 22 in the second, only 10 in the third, and 24 in the fourth quarter. Thus, the mortality from bronchitis was twice as great in the first as it was in the second quarter, and more than four times greater in the first than in the third quarter.

Very different were the facts as to pneumonia-of every 100 deaths from this disease, 32 on the average occurred in the first quarter, 27 in the second, 16 in the third and 25 in the fourth quarter. The mortality from pneumonia was only one-fifth greater in the first than in the second quarter, and only twice as great in the first as in the third quarter. The extreme winter fatality of bronchitis and its low summer fatality were equally wanting in the case of pneumonia.

A careful analysis of the weekly returns of the Registrarg-General of England and Ireland for ten years ending with 1885 and of the same returns for the year 1886, brings out a similar remarkable contrast between bronchitis and pneumonia, as to the time of year when these diseases are respectively most prevalent and fatal in London and Dublin.

Table I. contains the figures relating to bronchitis; Table II. those relating to pneumonia. Each Table sets forth the weekly average number of deaths in London and in Dublin from bronchitis and pneumonia, respectively, in the ten years, 1876-85, as well as the actual weekly number of deaths from these diseases in the year 1886 .

In Tubles III. and IV. these numerical results are thrown into curves.

It will be observed that the statistics for London and for Dublin agree to a remarkable extent. In both cities bronchitis falls to a very low ebb in the third, or summer, quarter of the year (July to September, inclusive), when only 12 per centum of the deaths annually caused by this disease take place in Dublin, and only 11 per centum in London. In the last, or fourth, quarter (October to December, inclusive), the percentage of deaths from bronchitis rises to 27 in Dublin and to 30 in London. The maximal mortality occurs in the first quarter (January to March, inclusive), when it is 38 per centum in both London and Dublin. In the second, or spring, quarter (April to June, inclusive), the deaths from bronchitis declined to 23 per centum in Dublin and to 21 per centum in London. 
The mortality from "pneumonic fever" is very differently distributed throughout the year. In the summer quarter more than 14 per centum of the deaths yearly referable to this disease are recorded in Dublin, and more than 15 per centum in London. In the first quarter, the figures are: Dublin, 31 per centum; London, 31 per centum; in the second quarter they are: Dublin, 30 per centum ; London, 26 per centum; in the fourth quarter they are: Dublin, 24 per centum; London, 28 per centum.

From these numerical results it, therefore, appears that the fatality and (indirectly) the prevalence of pneumonic fever from season to season do not correspond with the seasonal prevalence and fatality of bronchitis. The latter disease-be it of primary or secondary origin-increases and kills in direct relation to the setting in of cold weather, with excessive relative humidity and increased and frequent precipitation in the form of rain, snow or sleet, and hail. It subsides in prevalence and fatality with the advance of spring and the advent of summer.

Pneumonic fever, on the other hand, increases less quickly in winter and remains more prevalent and fatal in spring and summer than bronchitis; its maximal incidence coincides with the season of dry, harsh winds and hot sunshine in spring, when also the relative humidity is low, precipitation is scanty, while the diurnal range of temperature is extreme.

A closer study of Tables III. and IV. yields some interesting results. In the first place, we observe that the London curves of deaths both from bronchitis and pneumonia vary less from week to week than the corresponding curves for Dublin, which are much less regular and, as it were, more serrated. The reason for this evidently is, that in the case of London we have to deal with a population which is now some twelve times greater than that of Dublin, hence the law of periodicity fulfils itself with greater exactness in the vast population of London than in the comparatively small population of Dublin. The death curves of the larger city are, as it were, seen through a magnifying glass of ten diameters, in the corresponding death curves of Dublin, the variations from week to week being magnified or multiplied tenfold. In the second place, it will be noticed that bronchitis is uniformly throughout the year less fatal in proportion to the population in London than it is in Dublin, while the converse is true of pneumonia. According to the census of 1881 . the middle year of the decade with which we are at present concerned, the population of the London Registration District was 3,893,272 ; that of the Dublin Registration District was 348,293 . The average quarterly number of deaths from bronchitis in the ten years-1876-85 were these:-

First quarter, Dublin, 566.9 ; London, 4358.5.

Second quarter, Dublin, 338.2 ; London, 2397.1.

Third quarter, Dublin, 172.7; London, 1253.8.

Fourth quarter, Dublin, 395.4 ; London, 3413.2. 
On the other hand, the average quarterly numbers of deaths from pneumonia in the same ten years were:-

First quarter, Dublin, 112.2 ; London, 1467.2.

Second quarter, Dublin, 108.8; London, 1222.5.

Third quarter, Dublin, 51.4; Landon, 734.8.

Fourth quarter, Dublin, 85.9; London, 1850.2.

The third point of interest in Tables III. and IV. is the dip in the death curve from bronchitis, both in London and in Dublin, from the seventh to the tenth week of the year. This would seem to depend on several causes-first, the removal by death at the beginning of the year of those individuals who were most suseeptible to bronehitis; secondly, the acclimatisation of the surviving population to the continued cold of winter; and thirdly, the prevalence of gouthwest winds and open weather toward the close of January and early in February. With the setting in of the searching east winds of early spring the death curve again rises at the beginning of March, when also there is a marked rise in the deathtoll exacted by pneumonia, more especially in London.

Another curious point is, that the changes in the contour of the death curves apparently occur a week earlier in London than they do in Dublin, Delay in registration in the latter city seems to be the explanation of this otherwise puzzling circumstance.

It will be observed that in the foregoing analysis only statistics of deaths are considered, and these, unfortunately, are of minor value compared with statistics of the prevalence of bronchitis and of pneumonia respectively, were such available. Let us hope that the day is not far distant when registration of disease will be compulsory, as registration of the cause of death is at present. Until this much-needed reform is carried into effect, statistical inquiries into the prevalence of disease in localities and in seasons will want much of that precision which alone can give them scientifie value.

How are we to explain the continued frequency of pneumonic fever in summer and autumn? In my opinion the solution of this paradox is to be sought in the consideration of the pythogenic origin of the disease in many instances, and particularly in the warm season of the year. In a word, I would regard exposure to cold, extremes of temperature, harsh, drying winds, and other personal or climatological conditions as merely so many predisposing causes of the disease, while I would reserve for the introduction into the system of a specific virus or contagium the rôle of of an exciting cause-perhaps the sole exciting canse of pneumonic fever. As to the exact nature of that virus or contagium, we are as yet practically ignorant, but the researches and discoveries of Klebs, Eberth, Koch, and Friedlander in connection with the micrococei of pneumonia-the Pneumococcus (Pneumonie-kokken) of Friedländer, are full of promise. We stand on the threshold of a new Science of Medicine, and before long a 
flood of light will doubtless be shed upon the intimate nature and pathology of pneumonia as well as of other blood diseases.

In the "Medical Report of Cork Street Fever Hospital and House of Recovery, Dublin," for the year 1884, I ventured to assert that the claims of pneumonia to be considered a specific fever rested principally upon-

1. Its not infrequent epidemic prevalence, which the bibliography of the disease places beyond dispute.

2. Its proved infectiousness in some instances, as, for example, those observed at Dalton in the spring months of 1883 , by Dr. E. Slade King and Mr. Sloane Michell, M.R.C.S., England.

3. Its occasional pythogenic origin, and the remarkable correlation which appears to exist between it and enteric fever.

4. Its mode of onset, or "invasion," which exactly resembles that of the recognised specific fevers.

5. The appearance of constitutional symptoms before the development of local signs, or even local symptoms in many instances; in other words, the existence of a true "period of invasion."

6. The critical termination of the febrile movement in all uncomplicated cases.

7. The presence of local epi-phenomena in connection with the skin, such, for example, as eruptions of herpes, the appearance of taches bleuâtres, and the occurrence of desquamation.

8. The development of sequela in some cases, such as an attack of nephritis, followed by renal dropsy, ataxia like that observed after typhus or diphtheria, and so on.

9. The discovery of a bacterium in pneumonic exudation, to which analogy, at all events, points as pathognomonic.

In my hospital and private practice $I$ have acquired the habit of expressing the relation of the local lesion in pneumonia, or pneumonic fever, to the essential disorder, in terms of the intestinal lesion in enteric fever to that disease. Just as physicians and pathologists have long since come to avoid the dangerous error-I would even say heresy-of Broussais and his school, who beld that the pyrexia or feverishness in enteric fever was symptomatic of and secondary to a local inflammation of the glands of the small intestine, so we shall come in time to avoid the similar and not less dangerous but more widely disseminated error, of regarding the pyrexia in pneumonia as symptomatic of and secondary to a local inflammation of the lungs. The day is seemingly not far distant when we shall speak of "pneumonic fever" in precisely the same way as we use the term "enteric fever" at present-that is, to signify a zymotic or specific blood disease, munifesting itself after the lapse of a certain time-by physical phenomena-objective and subjective-connected, in this instance, with the lungs.

" Of. "The Practitioner." April, 1884. 


\begin{tabular}{|c|c|c|c|c|c|c|}
\hline \multirow{8}{*}{ 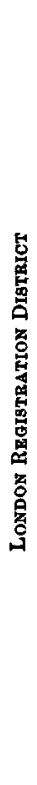 } & \multirow{2}{*}{ 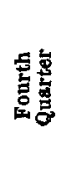 } & 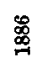 & 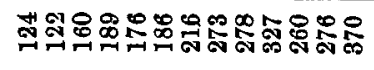 & 旅 & 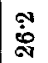 & \multirow{8}{*}{ 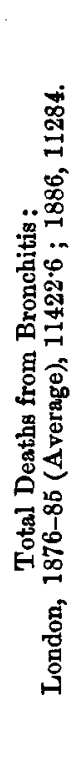 } \\
\hline & & \$్ & 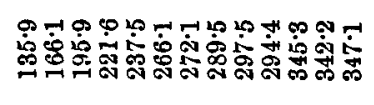 & 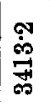 & $\dot{\infty}$ & \\
\hline & \multirow{2}{*}{ 焉昜 } & $\underset{\otimes}{\infty}$ & 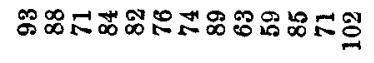 & 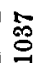 & $\stackrel{\leftrightarrow}{\dot{\sigma}}$ & \\
\hline & & 兽 & 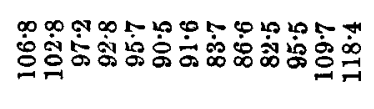 & 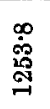 & $\stackrel{9}{\rightarrow=}$ & \\
\hline & \multirow{2}{*}{ 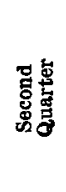 } & 总 & 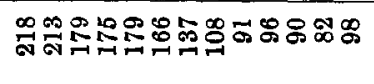 & 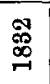 & $\stackrel{\substack{0 \\
\oplus}}{\oplus=1}$ & \\
\hline & & $\begin{array}{l}\infty \\
\infty \\
0 \\
0 \\
0\end{array}$ & 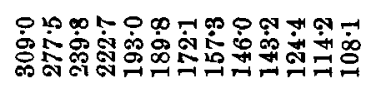 & 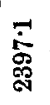 & $\stackrel{\stackrel{\leftrightarrow}{G}}{\circ}$ & \\
\hline & \multirow{2}{*}{ 总密 } & $\stackrel{\mathscr{\circ}}{\stackrel{\circ}{\sim}}$ & 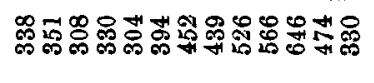 & $\begin{array}{l}\infty \\
\substack{\infty \\
10} \\
10\end{array}$ & $\underset{⿱ 亠 巾}{\infty}$ & \\
\hline & & $\begin{array}{l}\infty \\
\infty \\
0 \\
\infty \\
\infty\end{array}$ & 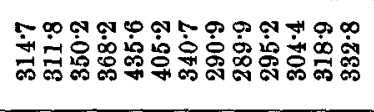 & 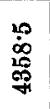 & $\begin{array}{c}\stackrel{\leftrightarrow}{0} \\
\dot{\infty}\end{array}$ & \\
\hline \multirow{8}{*}{ 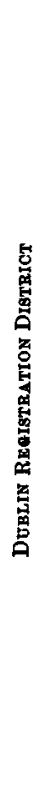 } & \multirow{2}{*}{ 爱 } & $\stackrel{\mathscr{*}}{\mathscr{\sim}}$ & 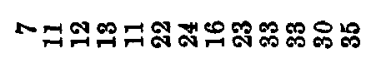 & 怘 & $\stackrel{P}{\text { \# }}$ & \multirow{9}{*}{ 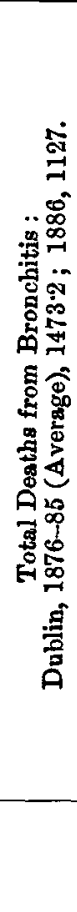 } \\
\hline & & $\begin{array}{l}\infty \\
0 \\
0 \\
0 \\
\infty \\
\end{array}$ & 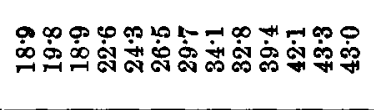 & 苞 & $\stackrel{\infty}{\infty}$ & \\
\hline & \multirow{4}{*}{ 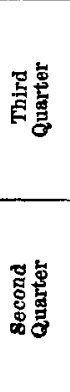 } & $\begin{array}{l}\mathscr{8} \\
\stackrel{\infty}{\leftrightarrows} \\
\end{array}$ & $\Rightarrow \infty m+\infty$ & $\stackrel{\infty}{\leftrightarrow}$ & 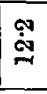 & \\
\hline & & 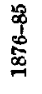 & 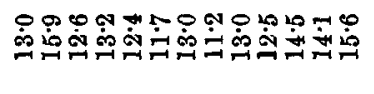 & 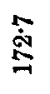 & 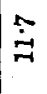 & \\
\hline & & $\stackrel{\infty}{\infty}$ & 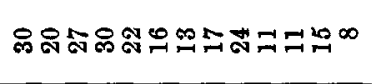 & में & $\stackrel{\sim}{\dot{\sim}}$ & \\
\hline & & 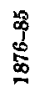 & 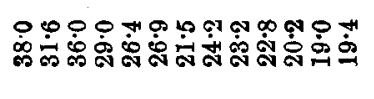 & 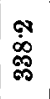 & : & \\
\hline & 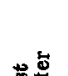 & $\underset{\mathscr{Z}}{\mathscr{\sim}}$ & 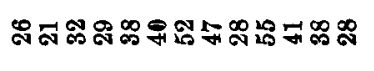 & $\frac{19}{7}$ & $\ddot{\text { ș }}$ & \\
\hline & 焉票 & क़్ & 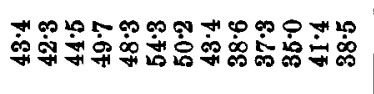 & क्ष & $\stackrel{\infty}{\infty}$ & \\
\hline & $\stackrel{4}{\$}$ & & 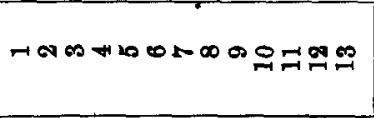 & 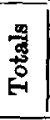 & 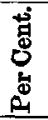 & \\
\hline
\end{tabular}




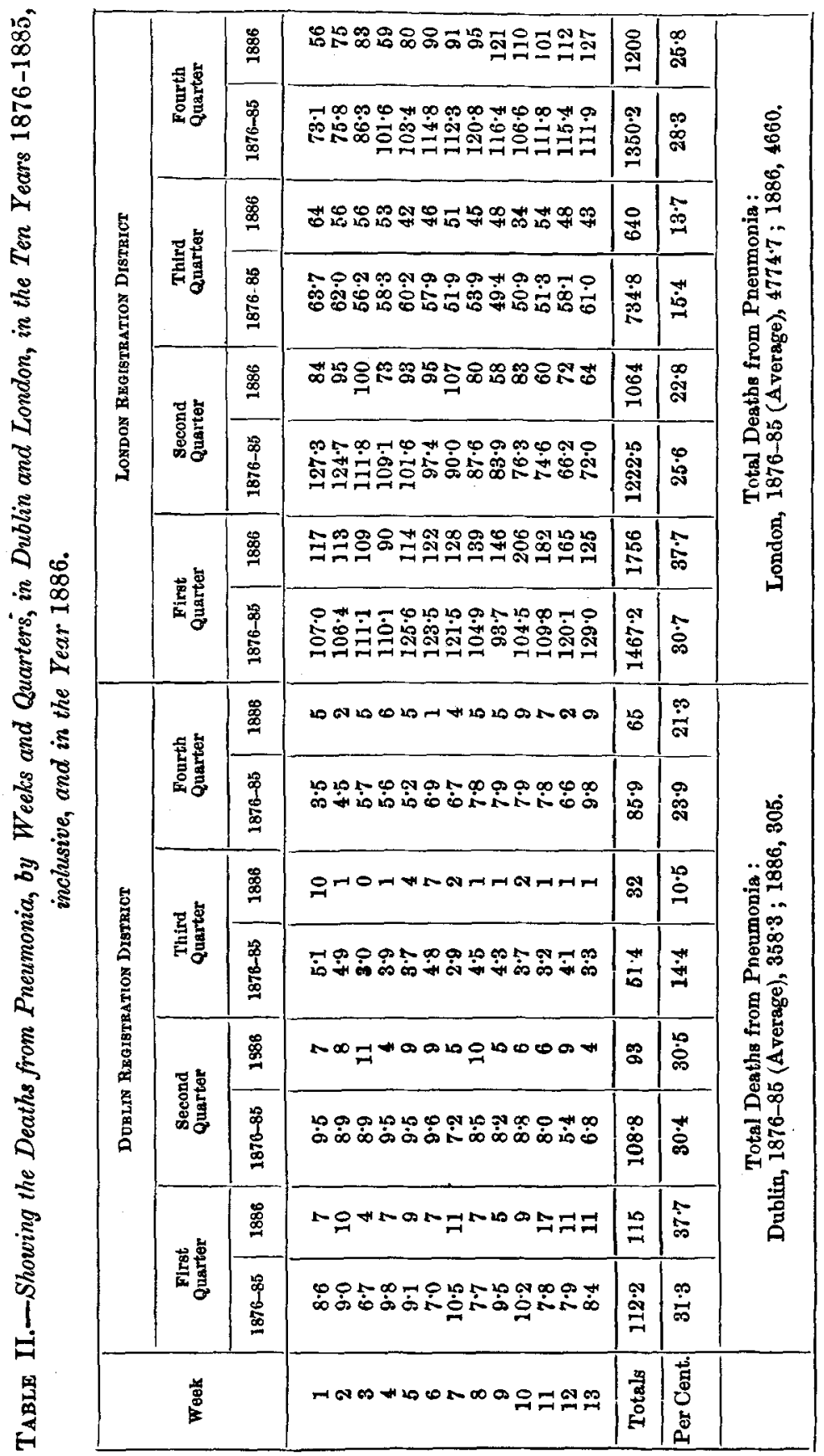

